\title{
The Human Elements of Child Story Books
}

\author{
Alebachew Mohammed Legas \\ Department of Psychology, Faculty of Social Science and Humanities, Debre Tabor University, Debre Tabor, Ethiopia
}

\section{Email address:}

alebemohaa@gmail.com

\section{To cite this article:}

Alebachew Mohammed Legas. The Human Elements of Child Story Books. International Journal of Literature and Arts. Vol. 7, No. 2, 2019, pp. 38-42. doi: 10.11648/j.ijla.20190702.11

Received: January 24, 2019; Accepted: March 18, 2019; Published: May 20, 2019

\begin{abstract}
Research has established that the transfer of knowledge is facilitated by similarity between the context in which the information is learned and the context in which it is to be applied. However, many learning contexts designed for young children reduce the similarity between learning and transfer by using fantasy contexts and or fantasy characters to teach information that is meant to be applied in the real world. Among this context the representation of human in the story plot Is an important focus thus, the general objective of this study is to assess the representation of human in Ethiopian child story books. To conduct a content analysis 30 teacher in 6 preschools rated the story books they mostly used to read or refer for story telling for children. Through this method the top rated 12 books were selected for analysis which contains a total of 97 stories. The finding indicates that majority of the story's $60(61.83 \%)$ bases their story's animal vs animal character, $31(31.95 \%)$ of the story mentioned about the family type. Among which $13(41.93 \%)$ of them are two parents, $14(45.16 \%)$ of single parent of which $8(57.14 \%)$ of them are single mom and $6(42.86 \%)$ single dad. Regarding child representation only 18 (18.75\%) of them involve children in the character of the story. Finally, the finding indicates $7(7.21 \%)$ of the story portrayed people with special need as their central character. Among which only $2(28.57 \%)$ of story represented people with special need in a appositive way. Thus, human representations in child story books are less emphasized and many focuses are given to the anthropomorphism character.
\end{abstract}

Keywords: Child, Family, Human Element, Special Need, Story Book

\section{Introduction}

Children's literature fosters personality and social development of Children which are very impressionable during the formative years, and children's literature can help them develop into caring, intelligent, and friendly people. Children in every culture learn to adopt certain roles and behaviors as part of the socialization process [1].

According to Richert et.al [2] the "proximity" of the story context to the real world affects the extent to which children transfer content from the book to reality. In three experiments, $3 \frac{1}{2}$ - to 6 -year-old children were presented with analogical problems in which the protagonists were either real people or fantasy characters. Children were more likely to transfer solutions from the stories about real people rather than the stories about fantasy characters. Furthermore, Anthropomorphism, animal characters as people, can add a degree of emotional distance for the reader/writer/ speaker when the story message is very powerful, personal and painful [3].

Ganea. et al [4] indicate that Presenting animals to children in ways that are similar to how humans act and behave is likely to be counter-productive for learning scientifically accurate information about the biological world and to influence children's view of the biological world. Thus, to investigate the balancing of anthropomorphic character and real human beings' representation in the story books is important. To see human element of child story books in line with the proportion of anthropomorphic main character; family depiction, child representation and disability in child story books.

Books serve as mirrors for children to see characters who look like themselves and have feelings and experiences similar to their own. The Family depiction celebrates the love they feel for their families and all the different varieties they come in. Whether they have two parent/single parent/orphaned etc, a big family or a small family no matter what kind of family they have, every family is special in its own unique way and should be represented in the story. 
Family systems theory contends that the family unit is comprised of four specific subsystems; marital, parental, sibling, and extended family. Each of these subsystems affects family interactions, family functions, and family members. Interactions between brothers and sisters provide children with their first socialization experiences. Through these interactions' children have opportunities to experience sharing, companionship, rivalry, and a range of other emotions [5].

Most people grow up in a family with at least one brother or sister. The relationship between siblings can be marked with rivalry and conflict, but can also be one of the closest and intimate relationships a person has in childhood, adolescence, and adulthood [6-7]. Although parents are a primary source of socialization, sibling interactions give children an opportunity to learn about their own and others' emotions, to share secrets, argue, and negotiate [8].

The birth of a child with special needs is a life-changing event for many families and influences the daily life of every member [9]. Research articles and books published on the topic of parental reactions to having a child with a disability and have stated that giving birth to, and bringing up, a child with special needs typically causes shock, denial, grief, anger, guilt, sorrow and a feeling of helplessness [10]. A study by Blaska examined 40 early childhood programs in Minnesota for literacy rich environments. A total of 1,677 books were reviewed for the inclusion of disability or illness. Of these books, 24 had some inclusion, representing $1.4 \%$ of the literature available for children's independent use. While most of the classrooms had an ample supply of books representing diversity of culture $(73 \%$ had 1-10 multicultural books available for students), few had books available that had characters with disabilities. Fifty-seven percent $(57 \%)$ of the classrooms had no books with characters with disabilities or illness. The remaining $42 \%$ had one or two books available [11].

Children with disabilities or illnesses need to see people similar to them. Perhaps no group has been as overlooked and inaccurately presented in children's books as individuals with disabilities. Most often they were not included in stories and when they were, many negative stereotypes prevailed such as characters who were pitiful or pathetic, evil or superheroes, or a burden and incapable of fully participating in the events of everyday life [12]. Often the difference or disability was the main personality trait emphasized to the reader, not a balance of strengths and weaknesses [11].

Although children's literature in book form is a relatively recent phenomenon in the context of Ethiopia, it has been an important part of the culture of the diversified ethnic groups in the country in its oral forms (folk tales, fables, legends, etc.) [13]. Currently looking this growing number of children's books demand many Authors are writing and translating child story books from foreign languages. Thus, this study assesses content of child storybooks inclusion of human element in their character/story and answer the following questions

a Is human represented in the story as a theme of character as port antagonistic and antagonistic? b What kind of family type represented in the child story book?

c Do children are represented fairly in their storybooks?

d Do people with spacial needs are represented fairly and positively?

\subsection{Significance of the Study}

This research is helpful for;

a The significant stakeholder (ministry of women, children and youth and ministry of culture and minister of education) will take a notice the value inherited by children through story book and so as will take appropriate measurement in awareness creation, training and appropriate measurement.

b It is supportive for the teacher, parent, child program journalist on television and radio and child story columnists in different newspapers and magazines to carefully select child story books to their child, schools and to mass medias accordingly

c Preschool, NGOS and other organizations and Institutions working with children will properly consider human element of the story book to the types of books they are going to buy, publish and or distribute for the children to their school/organization/institution or donation to other school/organization/institution.

$\mathrm{d}$ Those who are interested to engage themselves in writing children's story books (child literature) will consider accurate representation human (family, child, people with spacial need etc) their story themes.

\subsection{Scope of the Study}

The study was delimited to children's story books that are folk tales, heroic stories, historical/ realistic fiction, (but Songs, pictures and poetry can be found in the story) published in Amharic from 2015-2017 either translated or original Ethiopian authoring. Children's story books can raise a number of values or issues, but the study is not concerned with other values or issues raised in the narratives unless they have significance relation animal sex and gender responsiveness. Furthermore, this study not take all child literature unless they are story books (exclude non-storybased child literature like academic books, song books, poetry books, picture story books and alphabet books etc.)

\section{Research Design}

As it is an exploratory research the study uses the combined descriptive and textual analysis as basic methods.

This study analyzed 12 selected child story books (97child stories) written in Amharic from 2015-2017. The story books for analysis was selected by rating of randomly selected 30 teachers in 6 preschools about the story books they mostly used to read or refer for story telling for children.

This study excludes Amharic child story books published before the 2015, non-story child books, child story books written in other language and Amharic child story books 
written from 2015-2017 but not rated in top 12 books by preschool teachers.

Since the study is an exploratory with the units of analysis on children's books. The study will attempt to analyze focusing on what is presented in the text and or pictures and the overall them of the story by using Semiotics.

Textual analysis of the selected books has been conducted based on such signs, and both pro and anti-indicators of issues, themes, animals and person identified and described within the context of the story in line to the variable to be study.

Since this study primarily analyzed the content of child story books the researcher and the data collector/ Enumerators try to be free from biases through sticking with the criteria and interpreting the meaning without being subjective with referencing page number and quoting words, statements or pictures if appropriate from the story.

The data is analyzed using descriptive statistics (frequency and percentage) to describe category of story; family; child presentation and children with special need in the character. The qualitative analysis focus on narration of the representation of the above-mentioned criteria through words.

\section{Data Analysis and Interpretation}

\subsection{Type of Story Plot}

Table 1. Category of stories.

\begin{tabular}{llll}
\hline & Categories of the story & No & \% \\
\hline 1 & Animal vs animal & 60 & 61.83 \\
2 & Human vs human & 27 & 27.83 \\
3 & Human vs animal & 7 & 7.21 \\
4 & Human vs nature/plant & 2 & 2 \\
5 & Plant vs plant & 1 & 1 \\
& Total & 97 & $100 \%$ \\
\hline
\end{tabular}

As table 1 indicates the protagonist and the antagonist of the stories, majority of the story's $60(61.83 \%)$ bases their story's animal vs animal character followed by $27(27.83 \%)$ human vs human, 7 (7.21\%) of Human vs animal, 2 (2\%) of Human vs nature/plant and $1(1 \%)$ of Plant vs plant. Thus, more than half of the story is animal vs animal.

Studies indicate "proximity" of the story context to the real world affects the extent to which children transfer content from the book to reality. In three experiments, $3 \frac{1}{2}$ - to 6 -yearold children were presented with analogical problems in which the protagonists were either real people or fantasy characters. Children were more likely to transfer solutions from the stories about real people rather than the stories about fantasy characters. [2]

Thus, in terms of transfer of content knowledge children are less likely to transfer content information from fantastical books to the real world compared to realistic books. Furthermore, Burke and Copenhaver indicate Anthropomorphism, animal characters as people, can add a degree of emotional distance for the reader/writer/ speaker when the story message is very powerful, personal, and painful [3]. The Presenting animals to children in ways that are similar to how humans act and behave is likely to be counter-productive for learning scientifically accurate information about the biological world and to influence children's view of the biological world [4]. Thus, the balancing anthropomorphic character and real human beings are weak in the reviewed books. In addition, the story books supposed to teach children about environment through story since the issue of global warming and environmental change is challenge of the nation. In this regard only 1 story among the 97 narrate about environment (plant) which is less representative.

\subsection{Family Depiction}

Table 2. Type of family depicted in the story.

\begin{tabular}{|c|c|c|c|c|c|c|}
\hline 1 & Types of family & No & $\%$ & Type of single parent & No & $\%$ \\
\hline $\mathrm{A}$ & Two parents & 13 & 41.93 & \multirow[b]{2}{*}{ Single mom } & \multirow[b]{2}{*}{8} & \multirow[b]{2}{*}{57.14} \\
\hline B & Single parent & 14 & 45.16 & & & \\
\hline $\mathrm{C}$ & Orphan (lost parent) & 1 & 3.22 & \multirow{3}{*}{ Single dad } & \multirow{3}{*}{6} & \multirow{3}{*}{42.86} \\
\hline $\mathrm{D}$ & Lives with relatives & 2 & 6.44 & & & \\
\hline $\mathrm{E}$ & Parent with no children & 1 & 3.22 & & & \\
\hline & Total & 31 & 100 & Total & 14 & 100 \\
\hline
\end{tabular}

It is essential that children see themselves and their families in the literature they read. This helps them to increase their confidence and motivation and feeling of worthwhile and important. Among 97 stories reviewed 31 (31.95\%) of the story mentioned about the family type. Among which $13(41.93 \%)$ of them are two parents, 14 $(45.16 \%)$ of single parent of which $8(57.14 \%)$ of them are single mom and $6(42.86 \%)$ single dad. Thus $18(58 \%)$ of the family depicted are single, live with relatives or orphaned. However, the children grown in grandparent are not yet mentioned in the story books. According to the Central statistic authority, In Ethiopia, 71\% of children under 15 live with both parents, $14 \%$ live with only their mother, $4 \%$ live with only their father, and $10 \%$ live with neither parent. Nine percent of children live with their mother even though their father is alive, $2 \%$ of children live with their father even though their mother is alive, and 7\% live with neither parent even though both parents are alive [14]. Thus, the finding above table over emphasize single parent and deemphasize children live with relatives as well as parent without children.

Furthermore, understanding how children define a family is important when considering how they will respond to families in literature. Piaget interviewed 30 young boys ages 7 to 10 years and asked them to define a family. He found that youngest children included only persons living in the same home in their definition, often mentioning the house or 
the family name, but not a genetic (i.e., biological) relationship. Older children recognized the importance of biological relationships but only included relatives living in or near the home [15]. So that beyond sister and brother the story should include expected families like ant, uncles, step $\mathrm{mom} / \mathrm{dad}$, son/daughter of ant/uncle etc. According to Jeltova and Fish [16] "There is now acknowledgement that parents may be biological, adoptive, step, or foster, that they may be single or in a couple, and that they may be married, divorced, widowed, remarried. But the reviewed data indicate that the concept of family focus only on mom/dad and brother and sister which is not representative of the real world particularly the Ethiopian context living together as extended family.

\subsection{Child Representations}

Table 3. Sibling representation in the story.

\begin{tabular}{llll}
\hline & Sibling representation & No & \% \\
\hline A & Son & 1 & 5.5 \\
B & Daughter & 6 & 33.33 \\
C & Brother-brother & 8 & 44.44 \\
D & Sister-sister & 1 & 5.5 \\
E & Brother-sister & 2 & 11.11 \\
& Total & 18 & 100 \\
\hline
\end{tabular}

$\mathrm{N}=18$

As indicated in above table 3, depiction of child among 96 story reviewed the frequency of story involved children are $18(18.75 \%)$, from reviewed book presented people were mentioned 122 times, from this only $18(15 \%)$ of the frequency are related with children. This implies that majority of the story $79(81.44 \%)$ are not involving children rather focus on adult character and life style or they are animal character. Furthermore, when we compare people and animal presentation frequency, animal presentation frequency exceeds people which are 162 times whereas people presented 122 times.

Specifically, the story theme relatively deemphasizes the representation of Son, Sister-sister and Brother-sister relationship accordingly. On the other hand, Brother-brother relationship $8(44.44 \%)$ followed by single female child /daughter 6 (33.33) are well represented in the story. As Strohm [17] states, many researchers explored parents, their relationships between each other and with the child, their emotional field, financial situation, and many times siblings were the ones who were forgotten.

\subsection{Representation of Person with Special Need}

Table 4. People with special need in the story book.

\begin{tabular}{llll}
\hline & Inclusiveness in the story & Representation in the story & Representation of the person \\
\hline A & The blind & King & Positive \\
B & Sinziro (short person) & Wise & Positive \\
C & The 4 oxen & Black colour as ugly & Negative \\
D & Foolish person and the theft & Full person being stolen by theft & Negative \\
E & The fox without tail & Being embarrassed of not having a tail & Negative \\
F & A person with finger size & Praying to have a Hight & Negative \\
G & The fool Mamo & Fool Mamo caries donkey & Negative \\
\hline
\end{tabular}

Regarding disability character representation among the story reviewed as indicated in table 4 above 7 (7.21\%) of the story portrayed people with special need as their central character. Among which only $2(28.57 \%)$ of story represented people with special need in a appositive way in the case of sinziro, the wise short person and the blind king. The remain story $5(71.42 \%)$ represent people/animal with special need in negative ways. Furthermore, the story focus on foulness 2 (28.57\%), Height (being short) 2 (28.57\%), skin color, blindness and fox without tail 1 (14.28\%) respectively. In this regard all kind of special need was not represented in the story. More importantly character in the 6 $(81.75 \%)$ with special need are either animal or aged person, only one story was represented as children which special need in return create emotional distance for the reader.

According to the Dutch coalition on disability and development (DCDD) the estimated number of disabilities in Ethiopia is $17.6 \%$ [18]. Of which according to Ministry of education [19] 1.5-3 million children are school age children; thus, the child books are not well represented those children. Even the stated stories are reflecting negative attitude towards disability for the reader.

\section{Conclusion}

In analysis of the human element, the protagonist and the antagonist of the stories, majority of the story's bases their story's animal vs animal character followed by human vs human, Thus, more than half of the story is animal vs animal which impact transfer of content knowledge which children are less likely to transfer content information from fantastical books to the real world compared to realistic books. Among 
97 stories reviewed $31(31.95 \%)$ of the story mentioned about the family type of them are around $40 \%$ are two parents and single parent of which more than half of them are single mom. This finding is not related with central statistics authority (CSA) statistics composition of family in Ethiopian context. Regarding the involvement of children 18 (18.75\%), of the story involve them, furthermore reviewed book presented people were mentioned 122 times, from this only $18(15 \%)$ of the frequency are related with children. Finally, the finding indicates only $7(7.21 \%)$ of the story portrayed people with special need as their central character of which 5 $(71.42 \%)$ represent people/animal with special need in negative ways. Thus, the representation of human specially children in Ethiopian story are less emphasized which impact transfer of knowledge by loose context in which the information is learned and the context in which it is to be applied.

\section{Acknowledgements}

First, I would like to thank Debre Tabor University for financing this research to be conducted. Secondly, I would like to express deepest gratitude and appreciation for the instructors of psychology department and research and community service evaluation committee of the faculty and university for their contractive comment and suggestions in accomplishing this study.

\section{References}

[1] Kortenhaus, C. M and Demarest, J (1993) Gender Role Stereotyping in Children's Literature: An Update. Monmouth CollegeSex Rotes, Vol. 28, Nos. 314, 1993.

[2] Richert, A. R (2009) Learning from Fantasy and Real Characters in Preschool and Kindergarten. journal of cognition and development, 10(1-2): 41-66 Taylor \& Francis Group, LLC.

[3] Burke, C. L and Copenhaver, G, J (2004) Animals as People in Children's Literature. Language Arts, Vol. 81 No. 3.

[4] Ganea et al (2014) Do cavies talk? The effect of anthropomorphic picture books on children's Knowledge about animal. Front Psychol, volume 5.

[5] Turnbull, A., Turnbull, R., Erwin, E., \& Soodak, L. (2006). Families, professionals, and exceptionality: positive outcomes through partnerships and trust (5th ed.). Upper Saddle River: Merrill/Prentice Hall.
[6] Buhrmester \& Furman (1990). Perceptions of sibling relationships during middle childhood and adolescence. Child Development, 61, 1387-1398.

[7] Volling, B. L. (2003). Sibling relationships. Well-being: Positive development across the life course (pp. 205-220). Mahwah, NJ: Erlbaum.

[8] Lam, C. B., Solmeyer, A. R. \& McHale, S. M. (2012). Sibling Relationships and Empathy across The Transition to Adolescence. Journal of Youth and Adolescence, 41, 16571670 .

[9] Olsson, I. \& Roll-Pettersson, L. (2012). 'No no, you cannot say that!' Perceptions and experiences of parents of preschool children with intellectual disabilities in Sweden. European Journal of Special Needs Education, 27(1), 69-80.

[10] Avgustina Martirosyan (2013) Sibling Relationships in Families with a Child with Special Needs. Master's Dissertation Department of Special Needs of Education Faculty Educational Sciences university of Oslo.

[11] Blaska, Joan K. (2004) “Children's Literature That Includes Characters with Disabilities or Illnesses." Disability Studies Quarterly 24(1). http://dsqsds.org/article/view/854/1029.

[12] Volling, B. L and Blandon, Y. A (2003) Positive Indicators of Sibling Relationship Quality: Psychometric Analyses of The Sibling Inventory of Behavior (SIB).

[13] Simret Wondirad (2009). aspects of Ethiopian culture as reflected in Ethiopian children's literature in English. a thesis of Addis Ababa university school of graduate studies institute of language studies.

[14] Central statistic authority (CSA) (2014) Ethiopia Demographics Profile.

[15] Borduin, et al (1990) Development of the Concept of Family in Elementary School Children. The Journal of Genetic Psychology Research and Theory on Human Development Volume 151, 1990 - Issue 1.

[16] Jeltova, \& Fish (2005). Creating school environments responsive to gay, lesbian, bisexual, and transgender families: Traditional and systemic ap- poaches for consultation. Journal of Educational and Psychological Consultation.

[17] Strohm, K. (2002). Siblings: Brothers and Sisters of Children with Special Needs. South Australia: Wakefield Press.

[18] Dutch coalition on disability and development (DCDD) (2018). Ethiopia: definition, numbers \& types.

[19] Ministry of education (MOE) (2005). Ethiopian ministry of education report. 